\title{
Research on Practical Teaching System of Safety Engineering Major Based on " $1+X$ ” Model
}

\author{
Hui Huang* \\ School of Materials and Chemical Engineering \\ Ningbo University of Technology \\ Ningbo, China \\ Chunji Zhuang \\ School of Materials and Chemical Engineering \\ Ningbo University of Technology \\ Ningbo, China
}

\author{
Dan Qiu \\ School of Materials and Chemical Engineering \\ Ningbo University of Technology \\ Ningbo, China \\ Fengshuang Han \\ School of Materials and Chemical Engineering \\ Ningbo University of Technology \\ Ningbo, China
}

\begin{abstract}
The practical teaching of Safety Engineering major is facing the problems of short of practical teaching hardware, weak ability of practical teaching staff and rare opportunities for internships. The purpose of the work is to give references for practical teaching system construction of safety engineering major in new applied universities. This study proposed a " $1+X$ " model for the practical teaching system construction of safety engineering major. It contains " $1+X$ " model of construction of practical teaching hardware group, " $1+X$ ” model of the building of practical teaching staff group and " $1+X$ " model of establishment of the internship base group. Three implementation cases show the details of the implementation method. A case of student growth shows the initial effect of the established practical teaching system.
\end{abstract}

Keywords-practical teaching; safety engineering; model; group; case

\section{INTRODUCTION}

Safety production is a major event related to the safety of people's lives and property, a symbol of healthy economic and social development, and a requirement for the Party and government to be highly responsible for the interests of the people. The Party and the government have always attached great importance to the work of safety production, vigorously implemented the strategy of safety development, constantly strengthened the awareness of "red line" and "bottom line" of safety production, and paid attention to the training of highquality safety engineering professionals. In August of 2014, the State Administration of Work Safety Supervision and Administration and the Ministry of Education issued a guidance document on strengthening the training of industrial safety talents. The new Safety Production Law came into effect on $1^{\text {st }}$ of December of the same year. The Ningbo Safety Production Supervision and Administration Bureau and Ningbo University of Technology signed a framework agreement on strategic cooperation between the government and the university, and jointly established Ningbo University of Safety Engineering (also name as School of Safety Engineering, Ningbo University of Technology) on $24^{\text {th }}$ of December 2014. The School of Safety Engineering was officially established in

Industry-University Cooperation and Education Project of the Ministry of Education of China (201802066123); Ningbo Education Science Planning Project (2019YZD010).
July 2015, and has set up a major of safety engineering, relying on the management of the School of Materials and Chemical Engineering. According to the arrangement of the school, the major of safety engineering will train the professionals in the direction of industrial safety in Grade 2015, while in Grade 2016 and 2017; it will train the professionals in the direction of industrial safety and construction safety at the same time. As the only undergraduate college in Ningbo and the one fourth in Zhejiang with the major of safety engineering, there is lack of construction and development experience to be referred with two directions of major of safety engineering at the same time.

\section{PROBLEMS}

Practical teaching plays an important role in the training of safety engineering professionals [1]. However, as a new major, problems exist as follows:

\section{A. Short of Hardware in Practical Teaching}

The professional laboratory is the main place of experimental teaching in practical teaching. As an effective means and necessary way to cultivate students' practical ability and innovation ability, it can't be replaced by theoretical teaching. Due to the relocation of campus and the lack investment of funds, the construction of safety engineering laboratory lags behind the actual teaching needs [2].

\section{B. Weak Ability of practical teaching staff}

Good quality of practical teaching requires a good team of teachers. At present, there are only five teachers in the major of safety engineering, including three doctorates and two masters. Most of the teachers are new graduates who lack relevant practical teaching experience and engineering practice experience. The ability for practical guidance is weak.

\section{Rare opportunities for internships}

In addition to the lack of professional laboratories, the newly built major of safety engineering still lacks long-term, fixed social practice and internship units. The advantages of cooperation between government and school to explore resources for practical teaching of students at different learning stages have not been given full play [3]. 


\section{CURRENT SituATION ANALYSIS}

There are also some important opportunities for the construction and development of major of safety engineering.

\section{A. Major of Chemical Engineering and Technology Passes Engineering Education Accreditation}

As an advantageous major in the School of Materials and Chemical Engineering, the major of chemical engineering and technology has been universally recognized through decades of continuous construction. The chemical safety direction of the major of safety engineering can well promote its own improvement according to the principle of "not owned by me but used by me”.

\section{B. University Pays More Attention to the Construction of Major of Safety Engineering}

Recently, the university has discussed how to allocate special funds and sites for the construction of safety engineering laboratories to meet the basic needs of experimental teaching.

\section{Co-construction of Practical Examination Points for Special Operation}

The municipal safety training centers need to build special operation practical examination points in addition to the original theoretical training and examination points according to the latest requirements of the Ningbo Safety Supervision and Administration Bureau. After discussion, it was decided that the School of Material and Chemical Engineering should contribute to the construction of the first phase of the project jointly with the School of Continuing Education. Part of the original laboratory of major of safety engineering will be used as the examination sites to promote the construction.

\section{Further Developing the Advantage of Cooperation between Government and University}

The School of Safety Engineering will make some important progress in the following four aspects through the further promotion of the cooperation between the school and the Ningbo Safety Supervision and Administration Bureau. The school of Safety Engineering will straighten out the management structure, define the school characteristics, strengthen the construction of teaching staff and consolidate practical teaching.

\section{Practical Teaching System Construction}

Based on the above challenges and opportunities, It is proposed to construct a practical teaching system of major of safety engineering based on " $1+X$ " mode. The mode was implemented in order to ensure the smooth realization of the training objectives of applied safety engineering talents [4].

\section{A. “ $1+X$ ” Model of Practical Teaching Hardware Group}

The safety engineering professional practice teaching hardware group consists of the construction of safety engineering professional laboratory, the existing chemical engineering professional laboratory, the existing civil engineering professional laboratory, the construction of special operation practical examination point and safety technology service organization laboratory.

\section{B. “ $1+X$ ” Model of Practical Teaching Staff Group}

The team group of major of safety engineering practical teaching staff is built based on the existing safety engineering teachers. The staff's ability was improved through their own on-the-job learning and the guidance of chemical engineering professional practice teaching teachers and civil engineering professional practice teaching teachers. The team group also consists of part-time professionals from industries, universities and government.

\section{C. “ $1+X$ ” Model of Practical Teaching Internship Base Group}

The internship programme is carried out in different types of grass-roots safety supervision institutions and safety technology service institutions for the freshman, sophomore and junior year students. The internship for the senior year stidents is taken place in the production and manufacturing industrial enterprises.

\section{IMPLEMENTATION CASES}

\section{A. The case for " $1+X$ ” Model of Practical Teaching Hardware Group}

At present, the construction of safety engineering laboratory is being carried out in an orderly way. The first phase of bidding has been completed for 2.15 million experimental equipment, 500,000 experimental benches and 500,000 renovation and decoration projects. The first phase of construction can be completed and put into use recently. At the same time, the equipment software with a value of 1 million has been tendered and installed. The second phase of the project (safety simulation software and occupational health analysis and testing equipment) with a total price of nearly 3 million will also be tendered to ensure that it is fully completed and put into use in the near future. In addition, the use of chemical laboratories has been put into practice for the first time, and good results have been achieved. The courses of "Chemical Basic Experiment" and "Engineering Experiment" in Grade 2015 with 32 class hours (divided into 16 class hours of chemical simulation and 16 class hours of chemical principle experiment) were carried out with the help of inorganic chemistry laboratory, organic chemistry laboratory, chemical simulation laboratory and chemical principle laboratory under the chemical experiment center. Ningbo Qianye Testing Technology Research Co., Ltd., a safety technical service organization with C-level occupational health technical service qualification, has also reached an intention to use its laboratory as a practical teaching place for occupational health-related testing experiments to supplement the shortcomings of existing safety engineering professional laboratories[5].

\section{B. Case for “ $1+X$ ” Model of Practical Teaching Staff Group}

Three professional teachers of major of safety engineering have been assigned to Zhenhai District Safety Supervision and Administration Bureau, Haishu District Safety Supervision and Administration Bureau and East China Safety Science and Technology Co., Ltd respectively. At the same time, two teachers were arranged to participate in the engineering experiment course of the major of safety engineering of Grade 
2015, which was taught by five experienced teachers of major of chemical engineering and technology. The two teachers improved their practical teaching ability from the guidance and help of the teachers of major of chemical engineering and technology[6]. In addition, a group of government and enterprise experts including deputy director of Ningbo Safety Supervision and Administration Bureau, general manager of Ningbo Qianye Safety Technology Co., Ltd., general manager of Xianheng International (Ningbo) Safety Technology Co., Ltd., engineer of Nanjing Anyuan Science and Technology Co., Ltd., and senior engineer of East China Safety Technology Co., Ltd. were employed as part-time teachers. Each student was arranged with an enterprise instructor and a teacher from the major of safety engineering in the practice of the course of "School Year Papers I".

\section{Case for “ $1+X$ ” Model of Practical Teaching Internship Base Group}

The major of safety engineering has initially constructed different levels of internships according to the principle of "freshman knowledge and practice, sophomore professional practice". The internship base includes Ningbo Safety Propaganda and Education Consultation Day, Ningbo Public Safety Propaganda and Education Base, safety production supervision and administration institutions of government at all levels, and safety technology service institutions in Ningbo.

All freshmen majoring in safety engineering participated in large-scale propaganda and consultation activities on the spot as volunteers under the guidance of instructors, and assisted government departments, associations and scientific research institutes in the activities of Ningbo City Safety Propaganda and Education Consultation Day organized by Ningbo Municipal Government. At the same time, it also provides a wider understanding of the work in the field of safety products for the student participated [7]. The students experienced more than 80 safety experience projects involving transportation, public places, home, petrochemical industry, construction and other production safety in Ningbo Public Safety Publicity and Education Base through advanced technologies such as dynamic platform technology, live actors' virtual image interactive performance, and holographic sound display and so on. It gives a more intuitive understanding and feeling of the safety engineering expertise learned in the future through the interactive experience of crash experience, water accident rescue, safety theatre, CPR exhibition area, hidden danger elimination, housing safety and other exhibition areas with scientific and technological means and immersion experience mode.

48 students were assigned to 24 units and participated in a one-week professional internship in the practice section of the course of "School Year Paper I". The students further clarified the requirements and direction of professional learning while understanding the counterpart employment units and employment posts. In addition, there are still $1 / 3$ of the students are taking internship in the following semester, working at least one day per week in the original internship unit.

\section{CASE OF A STUDENT GROWTH}

A female student of Grade 2015 was assigned to practice in Ningbo Safety Supervision and Administration Bureau during the summer vacation of 2016. Under the guidance of government staff, she mainly assisted in the examination and verification of certificates of principal responsible persons, safety managers and special operators of enterprises. Through this practice, she had a preliminary recognition of three types of certificates in the process of enterprise safety production. At the beginning of 2017, she was assigned to practice in East China Safety Science and Technology Co., Ltd. Under the guidance of her supervisor, an engineer, she contacted the relevant contents of occupational health testing and safety evaluation report in the process of safety production. She had a preliminary understanding of the work of sampling on-site, laboratory analysis, inspection report and the occupational disease in the production-oriented enterprises. In the summer vacation of 2017, she also participated in a cooperation project of safety production supervision in 32 key enterprises. In those two months, she went to the enterprise site with schoolteachers and engineer experts to carry out safety hazard investigation and assist enterprise safety managers in making and improving safety management personnel, checking the account of safety production management and the final rectification of potential safety hazards in enterprises. She completed the process of "from ignorance to exclusiveness-leap of personal ability and quality" as mentioned in her personal summary from the above process, from contacting every point of the daily work of enterprise safety production to experiencing a relatively complete line in the daily work of enterprise safety production. The improvement has also been unanimously recognized by schoolteachers, Ningbo Safety Supervision and Administration Bureau tutors, enterprise engineer tutors and service enterprise leaders. It is believed that in the following year's learning process, she can continue to guide practice with theory, consolidate theoretical knowledge and deepen the understanding of theory through practice, promote the learning of theory with practice, and accelerate the growth of applied safety engineering talents.

\section{SUMMARY}

In recent years, the government and enterprises at all levels had paid more and more attention to the training of professionals who majored in safety. Up to now, about 200 colleges or universities have the major of safety engineering, most of whom set up this major in the last few years. This new major usually driven by the needs of local economic and social security development for newly built local colleges and universities. The problems like short of practical teaching hardware, weak teaching staff and lack of practical teaching internship base are commonly met for the newly built local colleges and universities. Therefore, it is of great significance to carry out relevant research.

Herein, some important opportunities for the current situation were analyzed from four aspects for the construction and development of the major of safety engineering. A " $1+X$ " model was proposed for the practical teaching system of major of safety engineering. It contains " $1+X$ " model of construction of practical teaching hardware group, " $1+X$ " model of the 
building of practical teaching staff group and " $1+X$ ” model of establishment of the internship base group.

Implementation cases for " $1+X$ " model of practical teaching hardware group, practical teaching staff group and practical teaching internship base group were well illustrated in detail. a Growth case of a student was given to show the initial effect of the established " $1+X$ " practical teaching system, good results could be expected. Continuous improvement is needed for better cultivating of safety talents in the future.

\section{REFERENCES}

[1] R.P. Tong, "Research on talent training mode for safety engineering major at universities," China Safety Science Journal, vol. 28, pp. 1-6, August 2018. (In Chinese)

[2] J. Liu, M.L. He, X.D. Zhao, and C. Wang, "Reform of practical teaching model of safety engineering-taking Hubei Polytechnic University as an example,” Journal of Hubei Polytechnic University, vol. 35, pp. 66-70, April 2019. (In Chinese)
[3] F.Q., Yang, B.H. Chen, and J. Yang, "Establishment of new experimental teaching system for safety engineering specialty in local colleges and universities," Higher Education in Chemical Engineering, vol. 32, pp. 51-56, December 2015. (In Chinese)

[4] Y.M. Shi, J.H. Ye, J. Zheng, and K.X. Li, "Construction of practical teaching system of safety engineering specialty under " $3+1$ " mode," Management Observer, vol. 9, pp. 101-103, March 2016. (In Chinese)

[5] F.L. Jiang, Y.J. Ye, L. Lei, X.Y. Li, and R. Yang, "Research and practice on the optimization of practice teaching system of safety engineering major oriented by professional accreditation: a case study of safety engineering major of Nanhua University,” Journal of Lanzhou Institute of Education, vol. 32, pp. 102-104, May 2016. (In Chinese)

[6] Z.T. Liu, Y.L. Yang, X.W. Li, Z.H. Li, and X.X. Zhong, "Research on practical teaching system of safety engineering specialty to strengthen the training of practical innovation ability,” Journal of Higher Education, vol. 2, pp. 15-17, January 2017. (In Chinese)

[7] C.P. Wang and W, L. Chen, "Exploration of the four-dimensional practical teaching model for undergraduates of safety engineering," Symposium on the 30th National Academic Annual Conference of Safety Science and Engineering in Universities and the 12th National Postgraduate Education for Professional Degrees in Safety Engineering, pp. 148-152, October 2018. (In Chinese) 